\title{
informe sobre ESTOCOLMO
}

Reportaje gráfico: P. Díaz Romeral
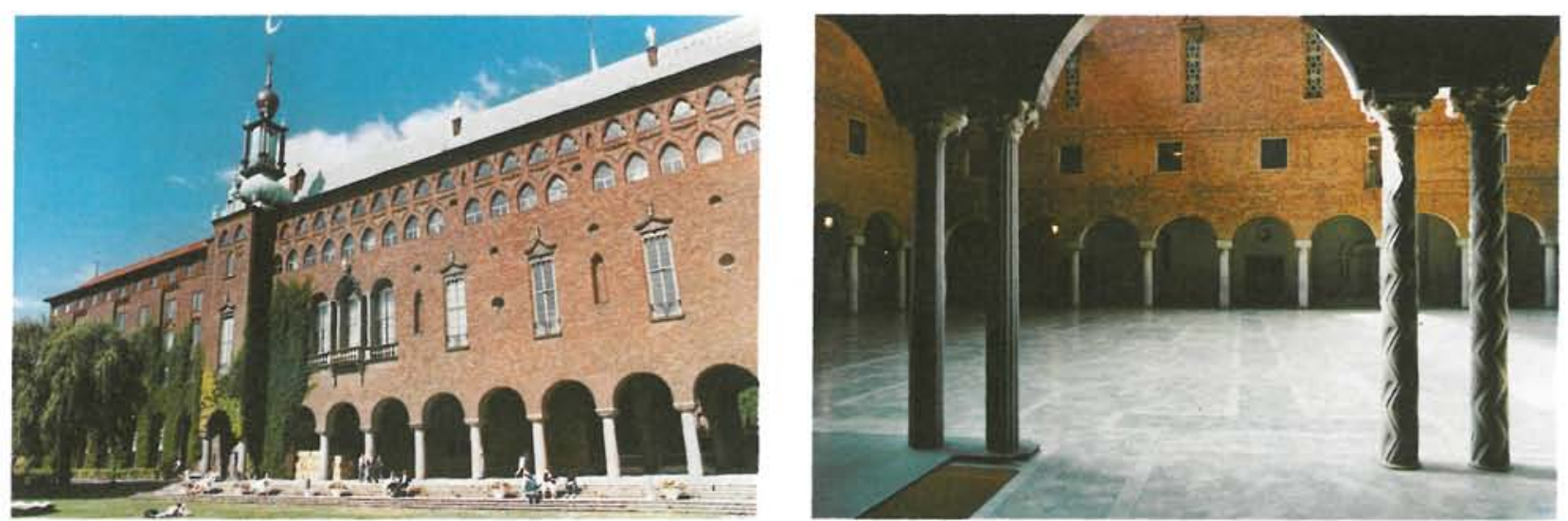

Ayuntamiento de la Ciudad (1923)

Estocolmo se desarrolló a partir del siglo XIII y tuvo su origen en una villa comercial emplazada en el lugar en que el lago Mälaren se encuentra con el mar Báltico.

Las primeras edificaciones se encuentran en islas que existen en este lugar, la Ciudad Antigua de hoy (Gamla Stan), cuyo plan urbanístico y edificios conservan aún en la actualidad mucho de su carácter medieval.

Durante el siglo XVI, Suecia como país se estabilizó y Estocolmo se convirtió en la ciudad más importante por su desarrollo.

Fue en el siglo XVIII en el que Suecia, durante un corto periodo, dominó el Báltico y cuando Estocolmo se expandió rápidamente.

Las bases del actual trazado en malla de las calles. en los distritos de Normalm y Södermalm, fueron establecidas entonces. Esta retícula fue ocupándose lentamente con edificios durante los siglos siguientes, primero con estructuras de carácter rural y más tarde con edificios de piedra de acuerdo con los modelos urbanos europeos.

Aproximadamente al final del siglo el centro de Estocolmo cambió de escenario desplazándose hacia el norte, al distrito de Nedre Normalm.

Después de la expansión de los años 1930, en su mavor parte, surgieron alejados de los distritos centrales nuevas comunidades en forma de suburbios. La presión de esta edificación extensiva ha tenido un importante influjo en el área central de la ciudad. El sistema de comunicación subterráneo y las anchas arterias para tráfico rodado han creado un nuevo patrón urbano.

El núcleo central de la ciudad ha cambiado completamente durante los últimos veinticinco años. 


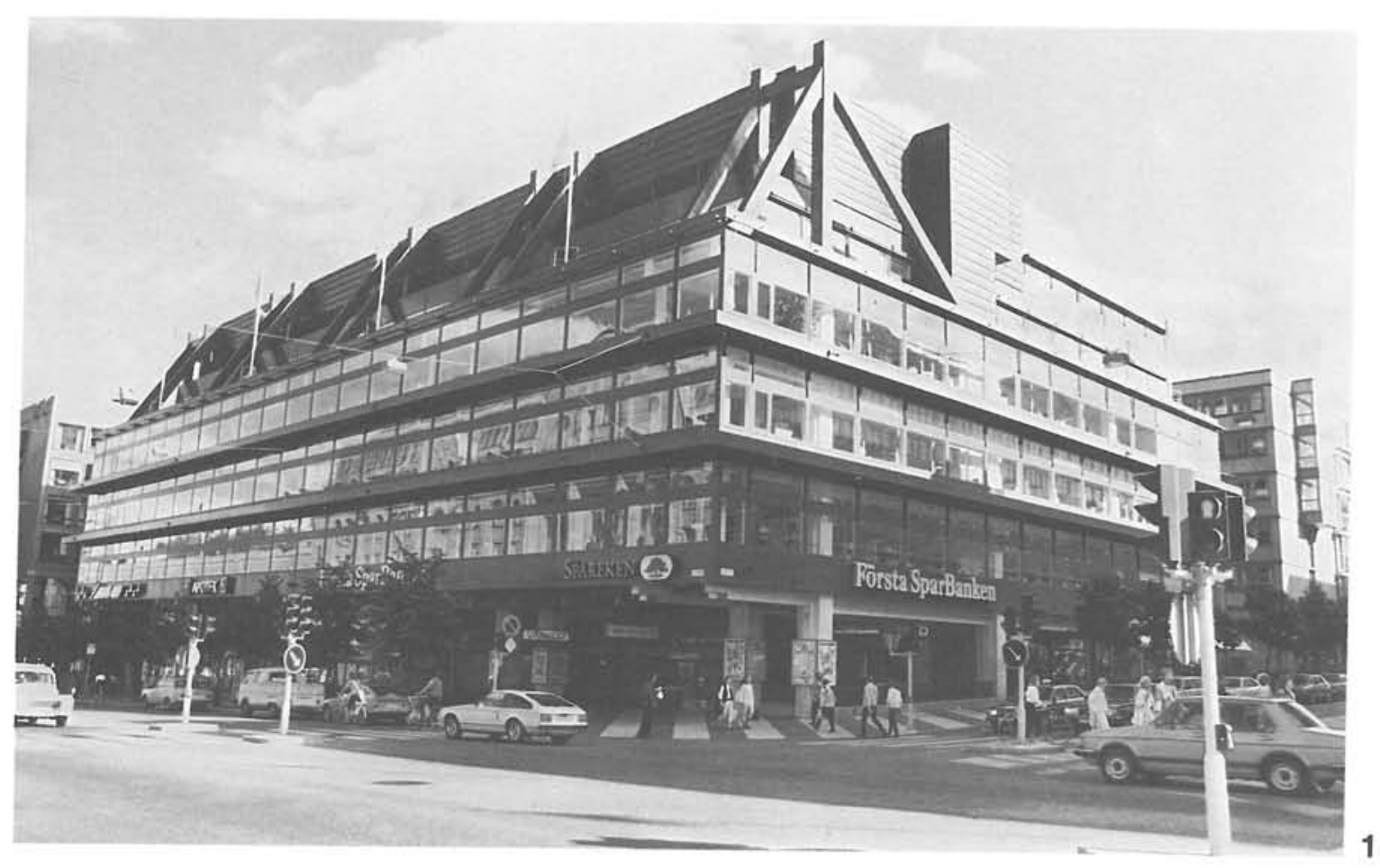

2
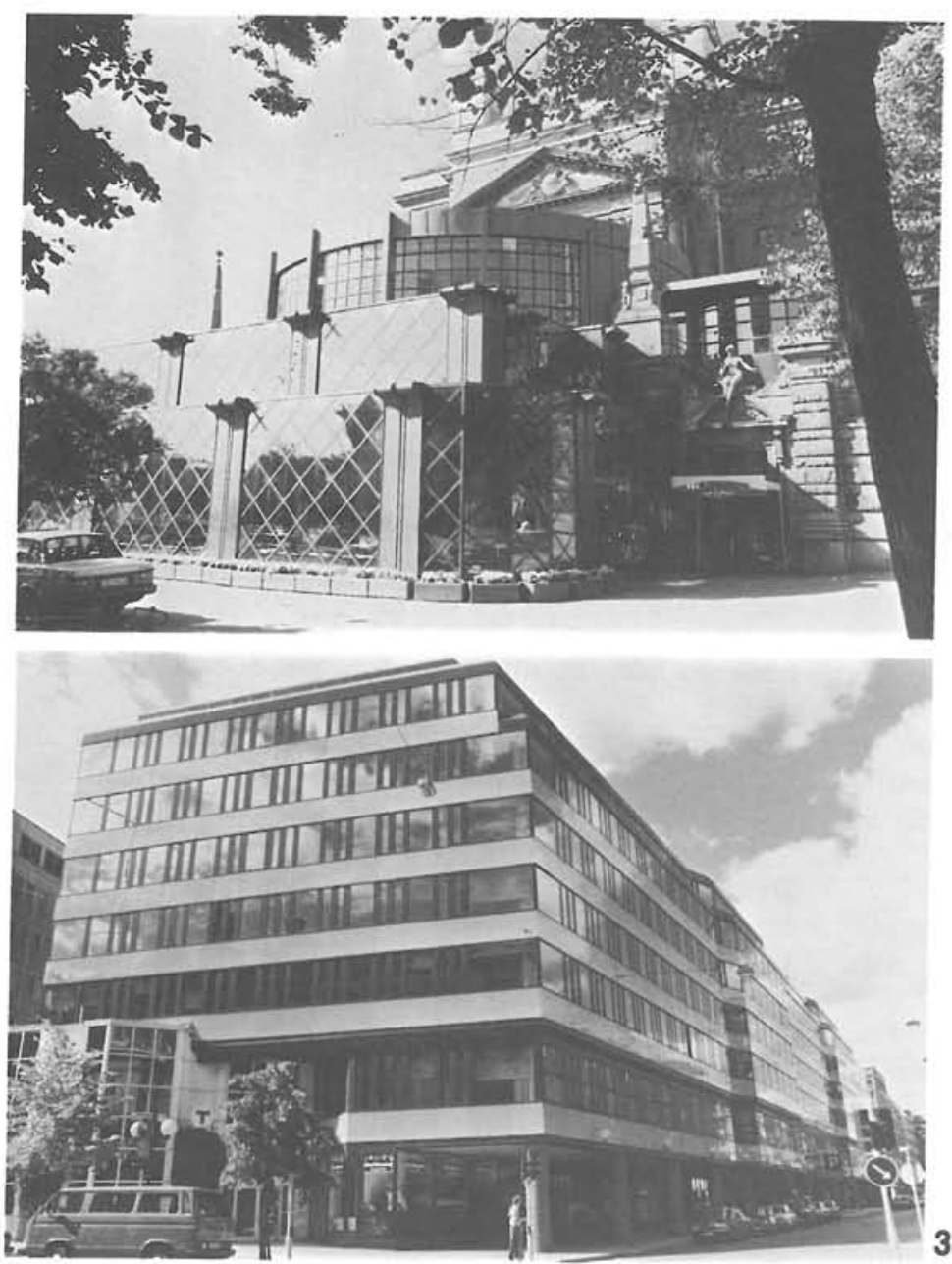

1.- SAVINGS BANK (1972-75)

Arq. Carl Nyrén

Edificio con un estudiado concepto del confort a través de patios interiores protegidos del viento y ruido de calle.

2.- NUEVO CAFE DE LA OPERA

Un logrado acuerdo entre dos concepciones arquitectónicas diferentes en el tiempo.

\section{3.- EDIFICIO DE OFICINAS}

Exponente del nivel alcanzado por el diseño nórdico aplicado a la arquitectura. 


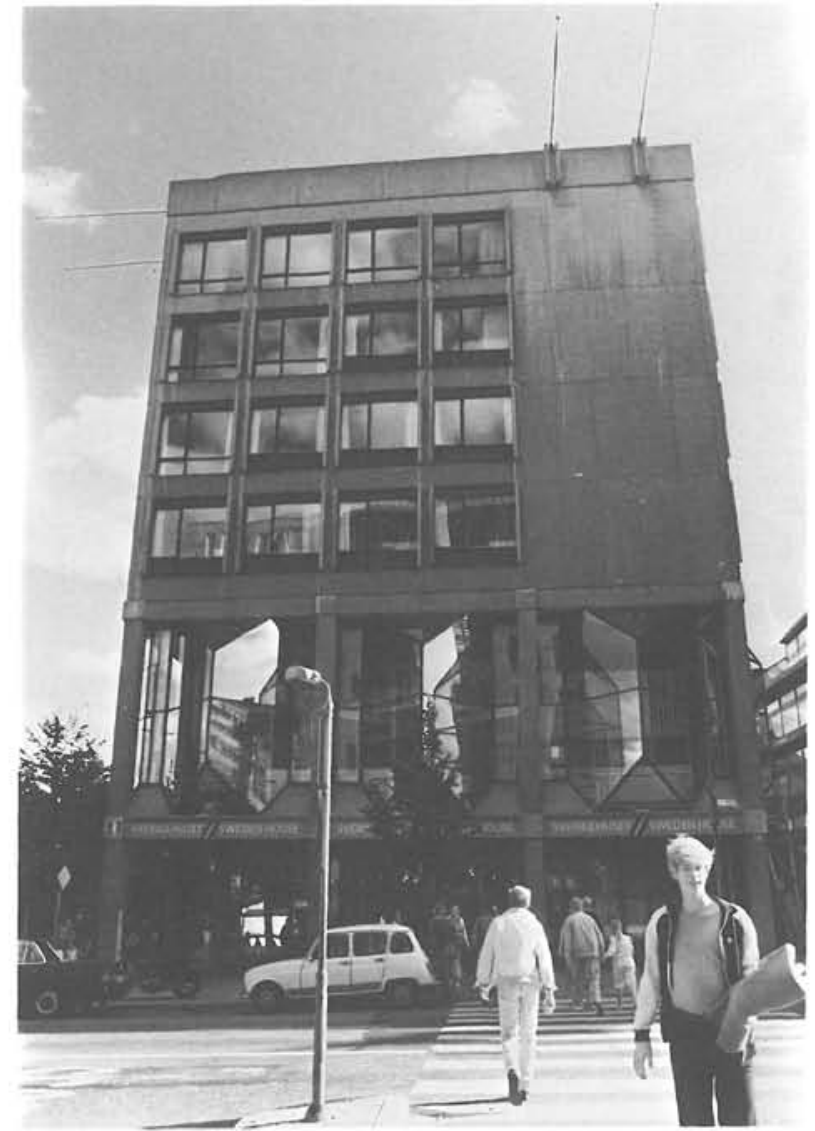

4

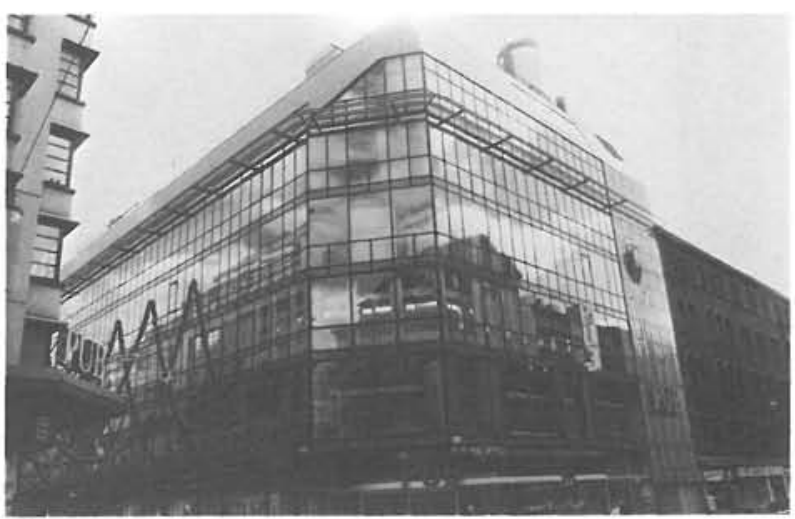

5

4.- CASA DE SUECIA

Arq. Sven Markelius

Todas las instituciones que proporcionan información cultural sobre Suecia se ha agrupado en este edificio.

5.- ALMACENES PUB Arq. Ey T. Ahlsen

6. - CENTRO DE ESTOCOLMO

Representó, en su momento, el concepto más avanzado de diseño urbano moderno.

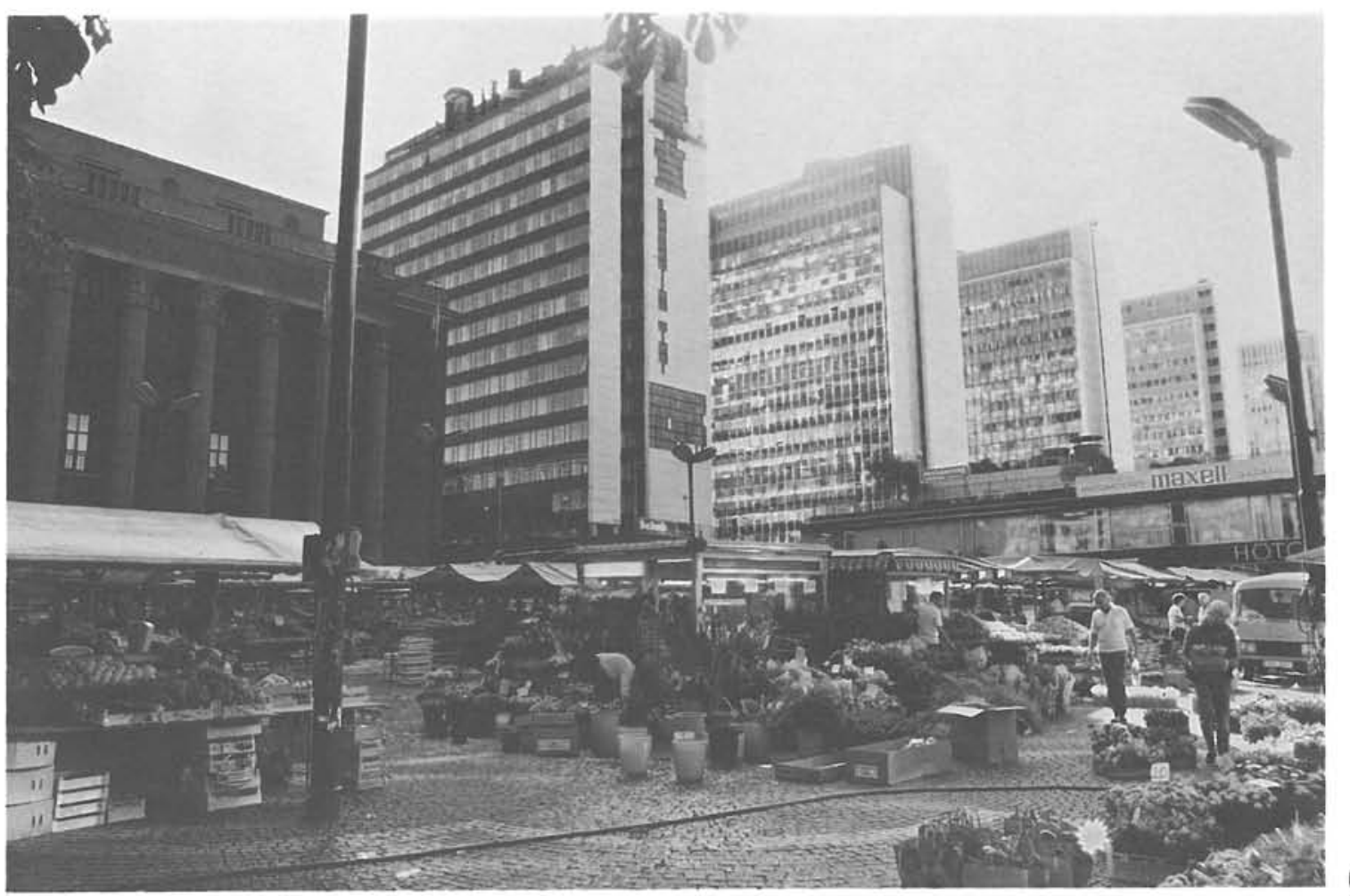




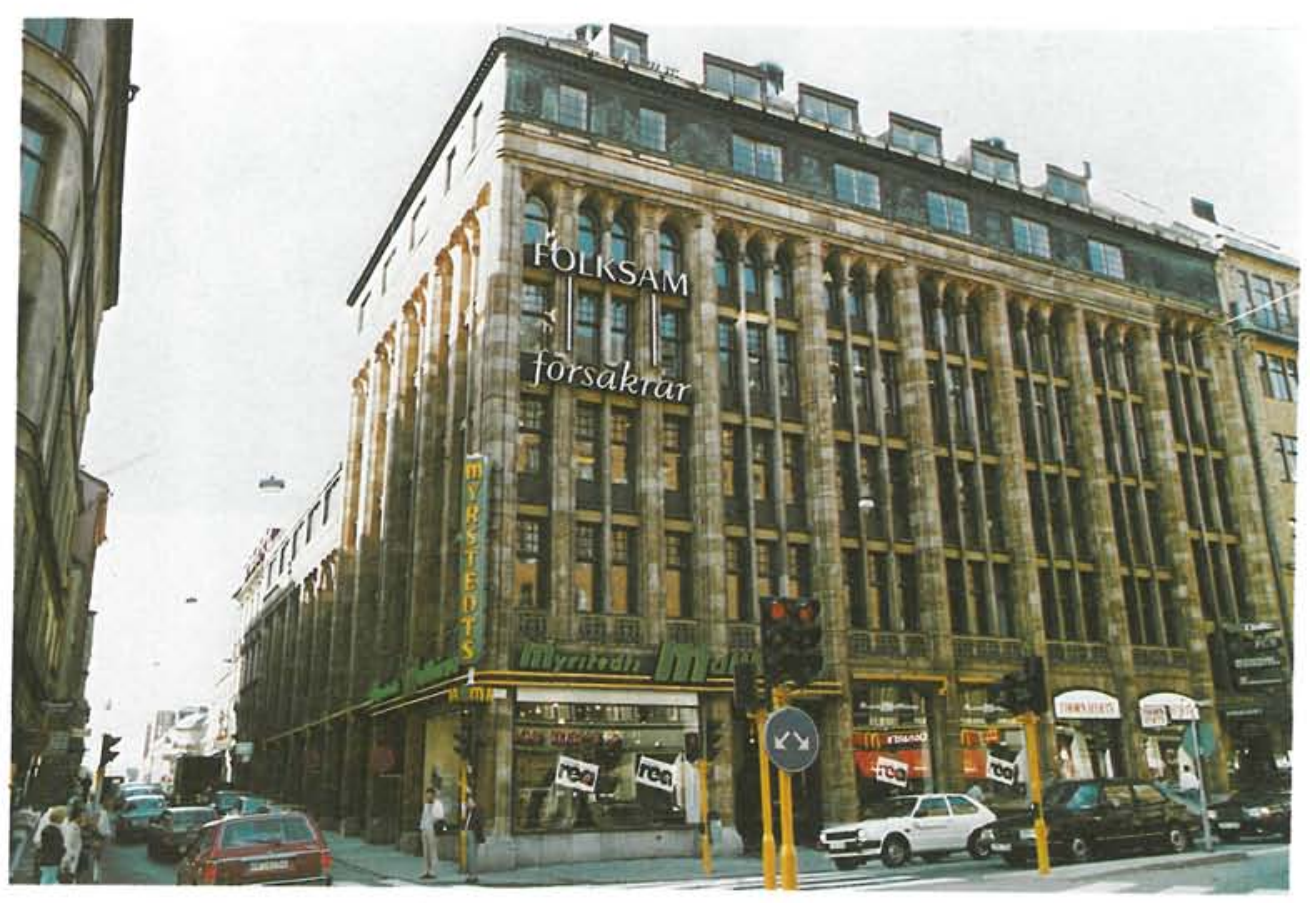

Algunos ejemplos de arquitectura comercial y residencial de comienzos de siglo.

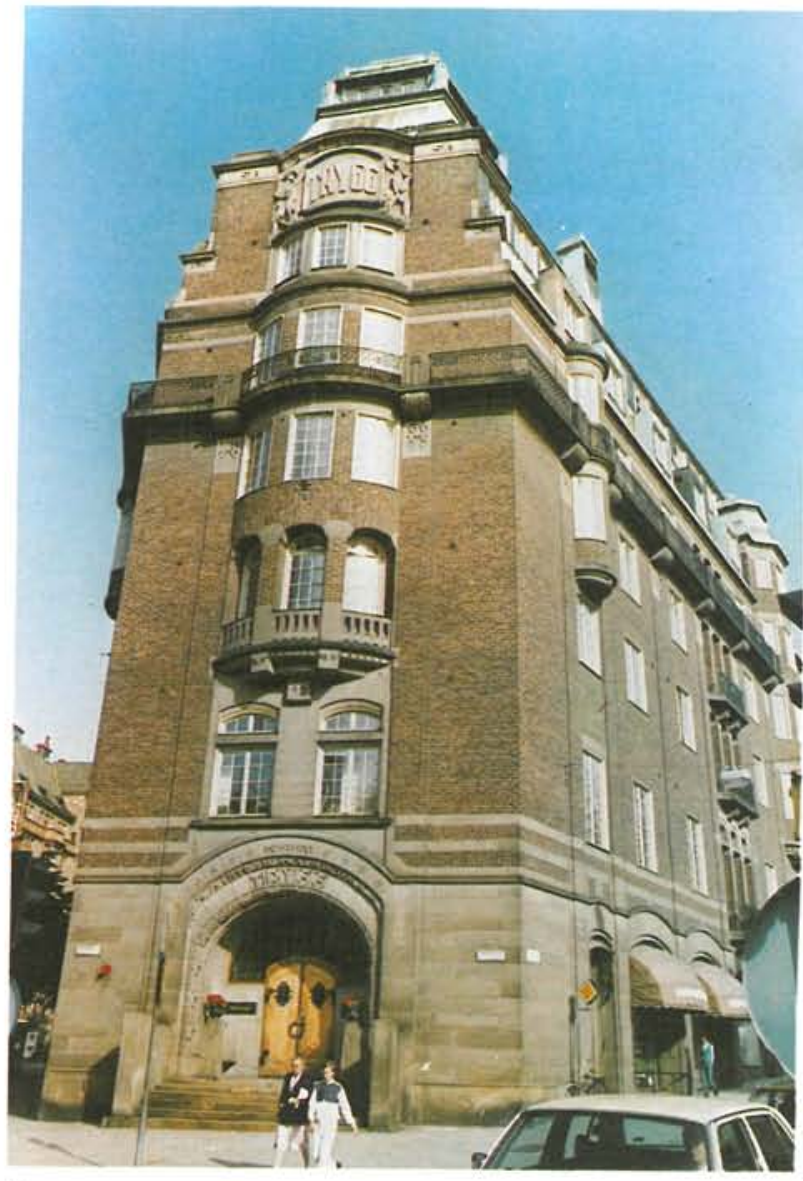

8

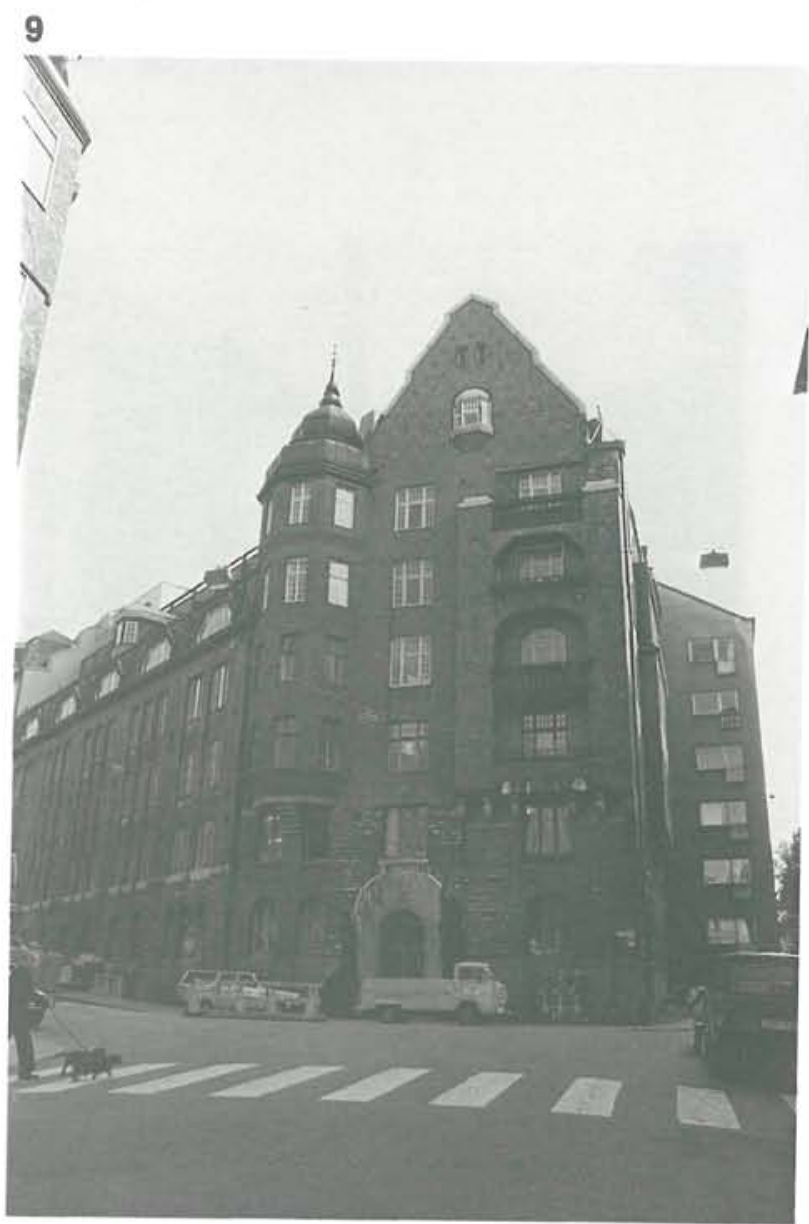




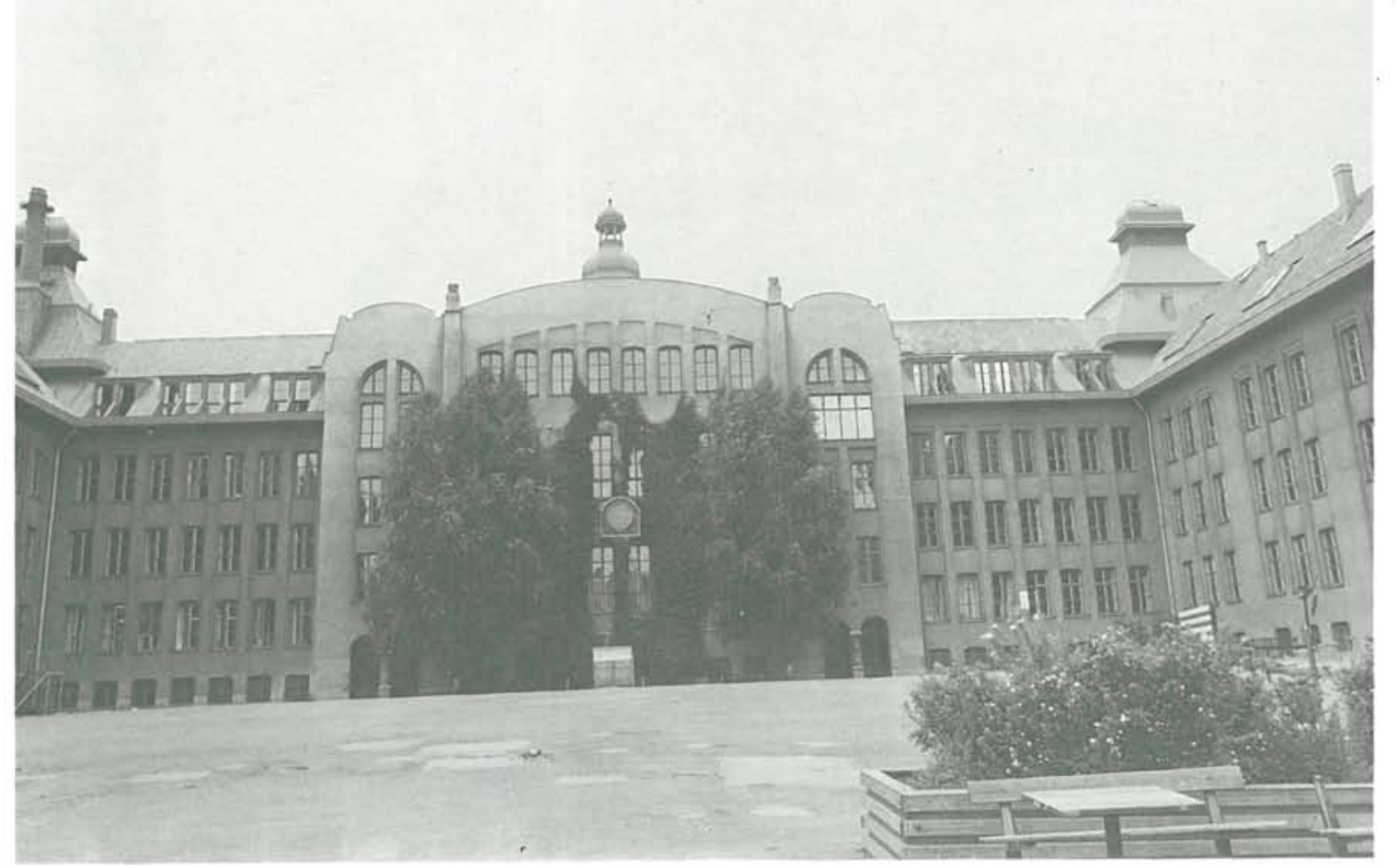

Un ejemplo de la corriente expresionista es esta escuela de Estocolmo.

11

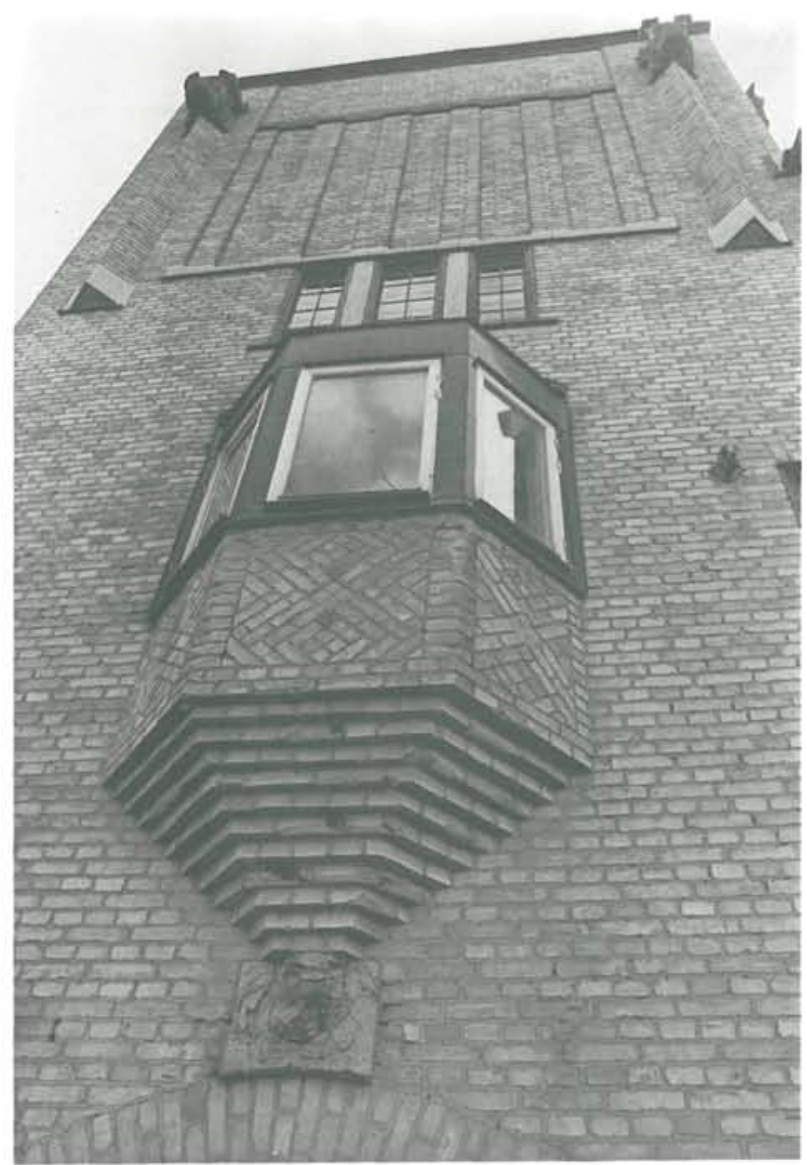

12

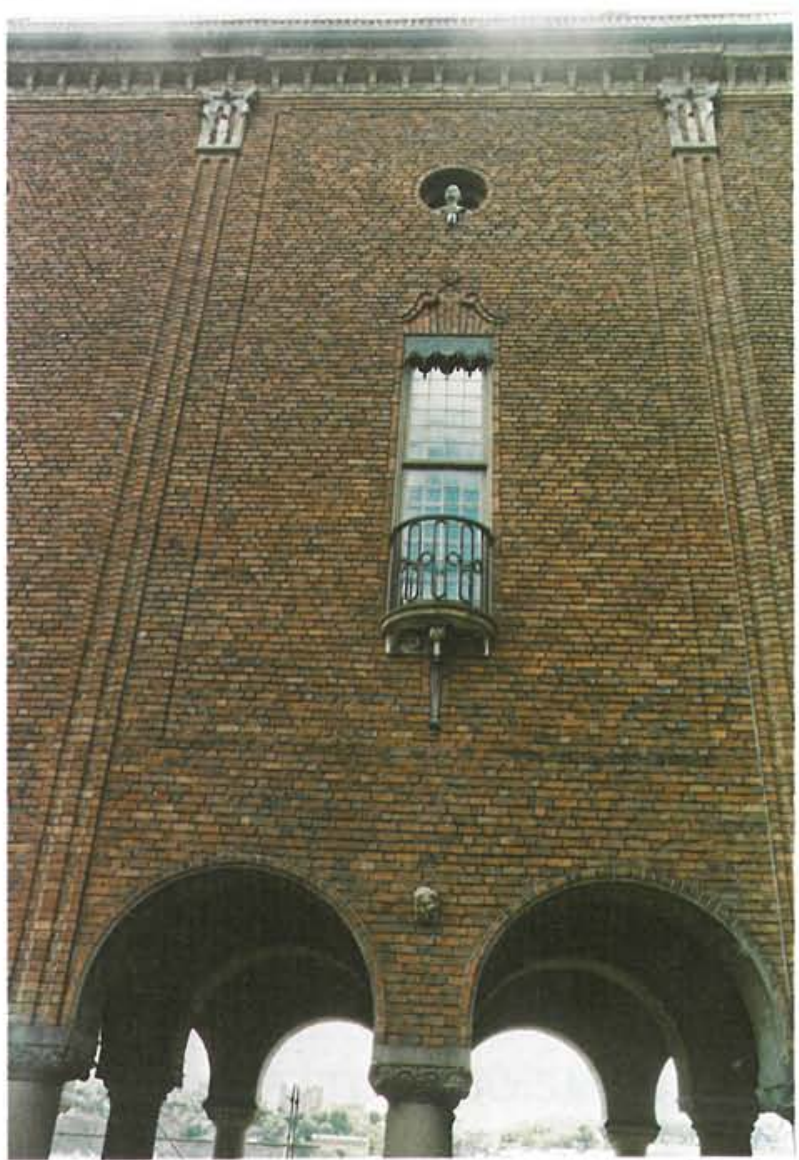

La tradición artesana nórdica en el empleo separador del ladrillo queda de forma patente expuesta en estos dos ejemplos. 